\title{
An Analysis of Product Lifetimes in a Technologically Dynamic Industry
}

\author{
Barry L. Bayus \\ Kenan-Flagler Business School, University of North Carolina, Chapel Hill, North Carolina 27599
}

\begin{abstract}
$\mathrm{T}$ he conventional wisdom that product lifetimes are shrinking has important implications for technology management and product planning. However, very limited empirical information on this topic is available. In this paper, product lifetimes are directly measured as the time between product introduction and withdrawal. Statistical analyses of desktop personal computer models introduced between 1974 and 1992 are conducted at various product market levels. Results indicate that (1) product technology and product model lifetimes have not accelerated, and (2) manufacturers have not systematically reduced the life-cycles of products within their lines. Instead, the products of firms that have entered this industry in the more recent years tend to be based on previously existing technology, and, not surprisingly, these products have lifetimes that are shorter than those of established firms. Implications of these findings are discussed.

(Product Life-Cycles; Personal Computer Industry; Failure Time Analysis)
\end{abstract}

\section{Introduction}

Conventional wisdom holds that product life-cycles are getting shorter over time. Based on statements in the popular press, such as "marketing consultants say product life-cycles are shortening every year" (Alsop 1986), “I can't document it, but every industry we look at seems to be undergoing shorter life-cycles" (Fraker 1984), and the usual "product life-cycles are getting shorter" claim in a large number of business articles, one would conclude that this is indeed a widespread phenomenon. This perception is especially evident in technologically dynamic industries like personal computers (e.g., Hof 1992, Verity 1992, Cimento et al. 1993, Steffens 1994). Believing that product lifetimes are shrinking in their industries, many firms have implemented new programs to accelerate the development of new products (e.g., Fraker 1984, Dumaine 1989, Patterson 1993). In fact, reducing the development time for new products and getting products to market faster has become an extensively discussed topic in the academic and business press (e.g., Rosenau 1988, Stalk 1988, Dumaine 1989, Patterson 1993, Stalk and Webber 1993).

A possible source of this popular notion relates to the technology S-curve concept. As discussed by Foster
(1986), the technology S-curve captures the relationship between the amount of resources (e.g., people, dollars) required to generate improvements in technological performance. In the early stages of technology development, a relatively large infusion of resources is needed to obtain incremental advancements in performance. As the technology becomes more familiar and widely used in products, performance improvements can be achieved with many fewer resources. During this period, technology development can proceed swiftly. In many instances, the resulting performance improvements are embodied in new product models, which are made available in rapid succession (Meldrum 1995). Thus, the dynamics associated with the general pattern of technology development can give rise to the idea that product life-cycles are getting shorter.

If true, shrinking product lifetimes have important implications for technology management and product planning. For example, shortening product lifetimes generally requires an increase in the percentage of revenues that should be spent on R\&D and new product development (e.g., Pierz 1995). The length of the product life-cycle also affects the amount of time available to recover an original R\&D investment (e.g., Goldman

MANAgEMENT Science/Vol. 44, No. 6, June 1998 
1982), and possibly to catch up to the technology leader (e.g., von Braun 1990, 1991). Should a firm be a market pioneer of new technologies that have shrinking product lifetimes, or a follower (e.g., Levitt 1966, Kerin et al. 1992, Schnaars 1994)? How is corporate decision making affected when products have market lifetimes that are becoming shorter (e.g., Eisenhardt 1989)?

Empirically, it is very difficult to rigorously examine product lifetimes, since detailed data for the entire product life-cycle and at all the various product market levels are generally difficult to acquire. Consequently, very limited empirical information on product lifetimes for any particular industry is available in the literature. The few published studies on this topic generally have taken indirect approaches using only aggregate data at the industry or product category level. For example, Qualls et al. (1981) examine sales growth rates for several durable product categories, Bayus (1992) studies first-time buyer diffusion rates for various consumer durables, and Grubler (1991) investigates household penetration rates of several products. See Bayus (1994) for a review of empirical efforts in this area.

Unlike these prior studies, this paper provides an indepth analysis of product lifetimes for different levels of product market aggregation in one technologically dynamic industry. Using data on all the product models sold by each manufacturer in the industry, product lifetimes of personal computers over the period 1974-1992 are investigated. Product lifetime is directly measured as the time between product introduction and withdrawal, and censored data are handled using the statistical framework of failure time analysis.

In the next section, a general discussion of the various product market levels that can be defined and analyzed is given. Background on the personal computer industry and the data empirically studied are discussed in the third section. This is followed by a description of the statistical model used for the empirical analysis of product lifetimes in the fourth section. Estimation results are then presented, and the implications of these empirical findings for firms and consumers are discussed in the last section.

\section{Product Market Levels and Analysis Issues}

Generally speaking, the product life-cycle concept is a description of the evolution of unit sales over the entire life- time of a product. The classical product life cycle has four stages (e.g., Levitt 1965, Cox 1967, Polli and Cook 1969): an initial introduction period of slow sales growth, a period of rapid growth in sales, a maturity period in which sales level off and are relatively stable, and a decline period in which sales drop off. Conceptually, the length of the product life-cycle (i.e., product lifetime) is the time between introduction and withdrawal from the marketplace. Depending on the level of product market analysis (see Figure 1), expected product lifetimes will vary. For example, product technology lifetimes generally are longer than product model lifetimes; product model lifetimes usually are longer than brand model lifetimes; and product category lifetimes rarely are observed. Note that the underlying product life-cycle for a product model is constructed by aggregating sales across all brand models of that product (across all manufacturers).

To reach the conclusion that product life-cycles are shrinking, the business press generally has used an indirect measure of product lifetimes. A common approach is to compare the household penetration rates (to some arbitrary level) for several product categories with the year of product introduction. Given that product lifetimes at the category level are relatively long, this indirect approach seems reasonable. However, any conclusions obtained across industries, product categories, or product forms may not necessarily be appropriate within a particular product form (i.e., product technologies, product models, or brand models).

Generally speaking, a firm's set of key competitors can be identified within a specific product category or product form. Shrinking lifetimes at the product technology or product model level imply a certain type of competitive environment faced by all firms in that industry - an environment in which the opportunity window in which to obtain a sufficient return on invested resources (including product development and marketing expenses) is getting smaller over time. In this case, getting to market quickly is paramount, since there is only a short time in which a firm can earn revenues.

On the other hand, shortening product lifetimes at the brand model level largely is influenced by an individual firm's decisions. Although a firm may perceive that speed-to-market is imperative, a simple but powerful analysis by von Braun $(1990,1991)$ shows that there are many conditions in which it is not in the firm's best interest to actively shrink its product lifetimes. The 
Figure 1 Levels of Product Markets

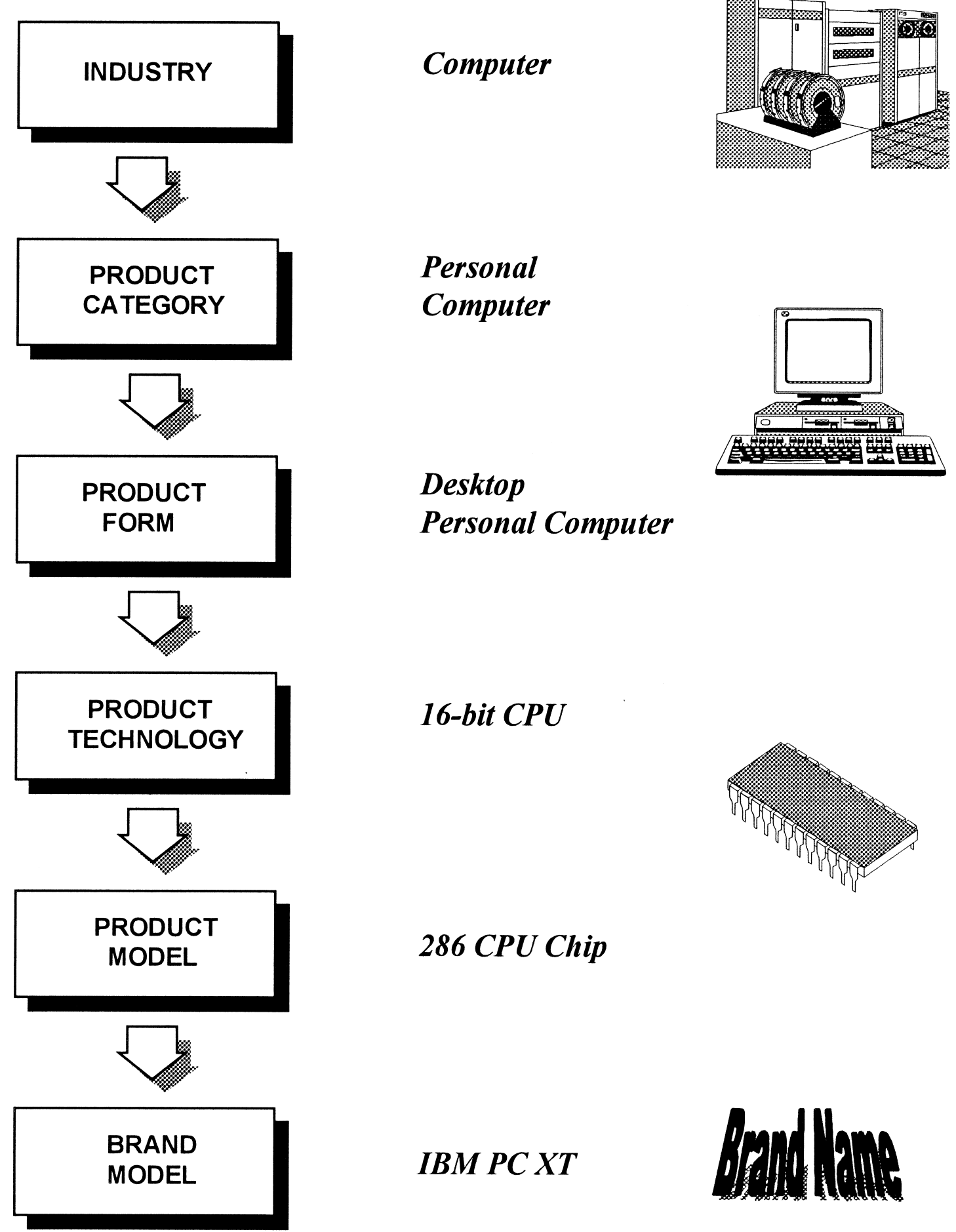

$\underline{\text { EXAMPLE }}$

Computer

Desktop

Personal Computer

16-bit CPU 
tradeoffs between time-to-market, product performance, and development costs must therefore be carefully balanced (e.g., rushing to market may lead to higher than expected development costs and / or product performance which is lower than anticipated). Stalk and Webber (1993) also note that blindly speeding new products to market can lead to a "strategic treadmill" where companies are "condemned to run faster and faster but always staying in the same place competitively" (e.g., Japanese consumer electronics companies are eliminating 25 models of VCRs and 19 models of televisions, and automobile manufacturers are extending their product cycles from 4 to 5 years).

In the remainder of this paper, the following analyses are conducted for one specific product form.

(1) Brand model information across all manufacturers is aggregated and then analyzed to determine if product technology or product model lifetimes are shrinking over time.

(2) The brand model lifetimes within a firm's product line are analyzed to determine if brand model lifetimes within manufacturers are shrinking over time.

(3) Brand model lifetimes across manufacturers are analyzed to determine whether competing firms are pursuing strategies involving different product cycles over time.

\section{The Personal Computer Industry}

A personal computer can be defined as a generalpurpose, single-user machine that is microprocessor based and can be programmed in a high-level language. The central processing unit (CPU) is the "brain" of the computer. It contains the arithmetic and logic component, as well as the core memory and control unit for the computer. As such, it controls all system operations, including the external peripheral equipment. Since CPU chip design determines the overall computer power and performance, it is the single most important factor used by manufacturers to define a brand model. ${ }^{1}$ Langlois

\footnotetext{
${ }^{1}$ As discussed in Steffens (1994), manufacturers generally use unique brand model names for personal computers with different CPUs and incur significant expenses with the production and launch of each model. Also note that separate brand models for each of the different speeds within a particular microprocessor family are often used. Multiple memory, display, sound, and communication configurations typically are then possible within any brand model and can be changed at the time or purchase, or even later. The few cases in which a brand model name could not be associated with a unique CPU chip were deleted from the database analyzed in this paper.
}

(1992) and Steffens (1994) provide an excellent historical review of the personal computer industry.

First-generation microprocessors (e.g., Intel's 4004) were used in calculator applications and were generally incapable of performing the tasks associated with personal computing. The first personal computers were developed around second-generation 8-bit processors. ${ }^{2}$ These CPUs included Intel's 8080 (introduced in 1974) and 8085 (introduced in 1976), Zilog's Z80 (introduced in 1975), and Mostek's 6502 (introduced in 1975). Second-generation personal computers were based on third-generation 16-bit microprocessors. These CPUs included Intel's 8086 (introduced in 1978), 8088 (introduced in 1979), 80286 (introduced in 1982), and Motorola's 68000 (introduced in 1978) and 68010 (introduced in 1979). Third-generation personal computers are based on CPUs with a 32-bit architecture (i.e., fourth-generation processors). Full 32-bit processors include Intel's 80386DX (introduced in 1985), 80386SX (introduced in 1988), 80486DX (introduced in 1989), 80486SX (introduced in 1991), and Motorola's 68020 (introduced in 1986) and 68030 (introduced in 1989).

As this brief discussion indicates, the personal computer industry provides a technologically dynamic setting in which to study product lifetimes. In addition, it is generally believed that the product lifetimes of personal computers are getting shorter over time (e.g., Hof 1992, Verity 1992). Although the calculation details are lacking, Cimento et al. (1993) also report that the lifetimes of personal computers introduced by U.S. firms declined from around 2.5 years in 1988 to 1.5 years in 1991.

\subsection{Data}

Using the available brand model information from International Data Corporation's Processor Installation Census, a database composed of annual unit sales (domestic and international), ${ }^{3}$ the year of product introduction, and the installed CPU for all the desktop per-

\footnotetext{
${ }^{2}$ This information was assembled with the assistance of Nancy Pressel from Intel Corporation.

${ }^{3}$ As discussed in the previous section, product lifetime is directly related to the potential revenues that can be earned. Thus, to obtain a more complete measure of the time in which a brand model is in the market, sales across domestic and international markets are studied in this paper (see also Langlois 1992). Although not reported here, analyses of product lifetimes defined using only domestic sales resulted in similar conclusions to those to be presented in $\$ 5$.
} 
sonal computer brand models introduced between 1974 and 1992 was developed. Any desktop model with a CPU chip that could not be uniquely identified (e.g., due to proprietary manufacturer technology) was eliminated from the database. The resulting data set includes information on over 600 manufacturers and almost 2800 brand models. The annual number of new entrants and new brand model introductions between 1974 and 1992 is given in Figure 2. Each is characterized by the same pattern, in which there is a gradual increase to a peak in the annual number of new entrants and new product introductions followed by a decline over time. This general pattern is consistent with that of a maturing industry that has established a dominant product design (e.g., see Rosegger and Baird 1987, Utterback 1994).

Figure 3 shows the total annual desktop personal computer industry sales between 1974 and 1992, along with sales for each product technology generation. Total personal computer sales have continued to grow over

Figure 2 Annual Entrants and New Product Introductions in the Personal Computer Industry

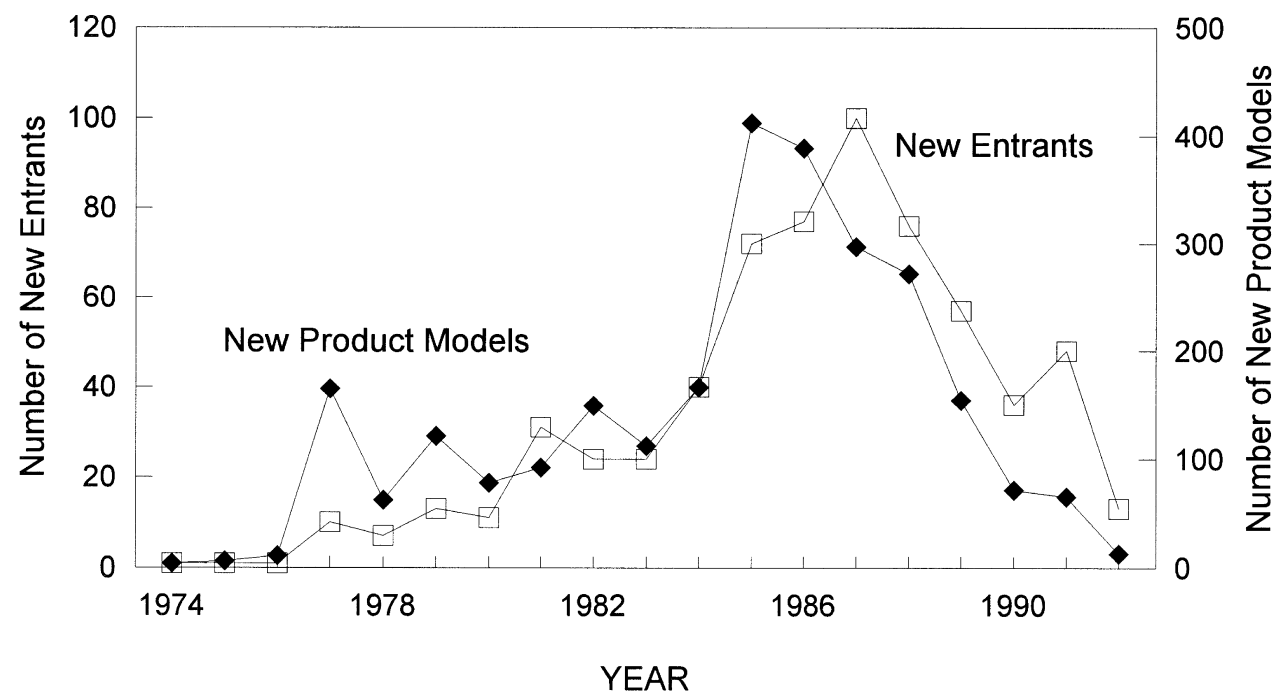

Figure 3 Annual Personal Computer Sales by CPU Technology Generation

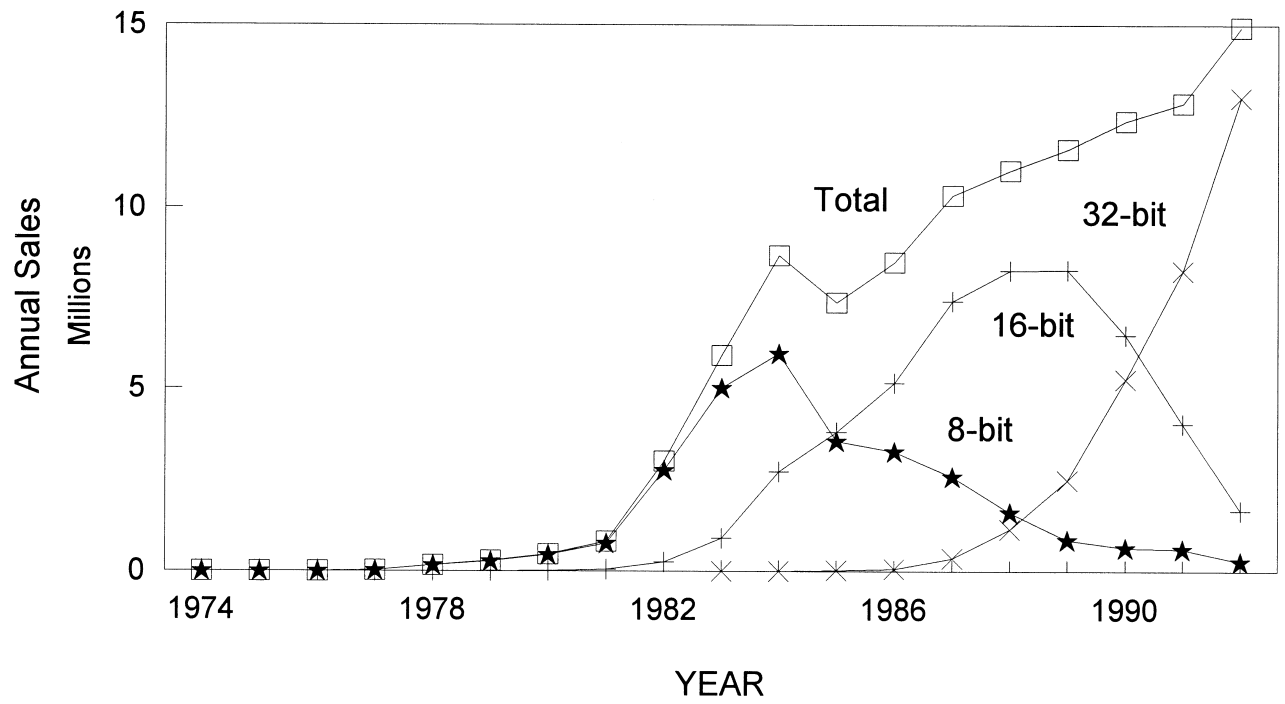




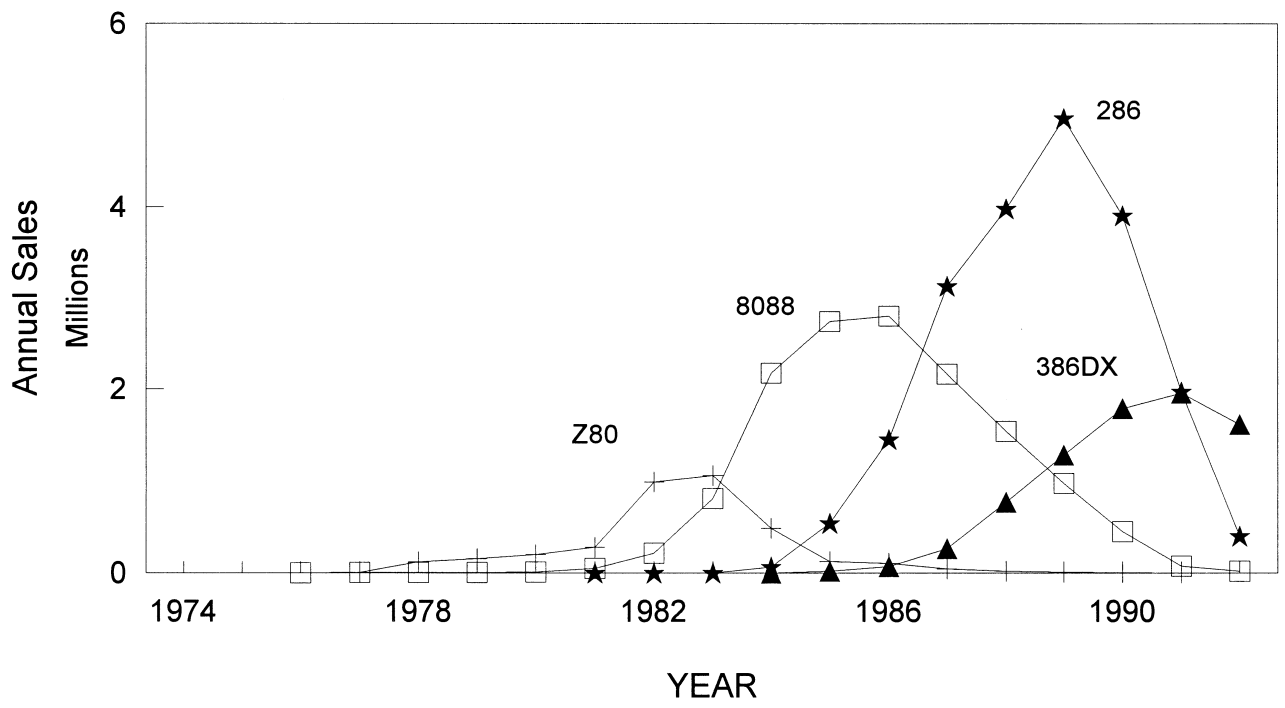

this period, reaching an sales level of almost 15 million units in 1992. Sales within each technology generation resemble the usual product life-cycle pattern. For example, sales of first-generation personal computers (based on 8-bit CPUs) grew slowly from fewer than 100 units in 1974, reached a peak of almost 6 million units in 1984, and have generally declined thereafter. As shown in Figure 4, total annual sales for personal computers based on various microprocessor chips also follow the general product life-cycle shape. Note that these diagrams contain truncated data, so one cannot necessarily conclude that the product technology and product model lifetimes are shrinking over time (e.g., 8-bit and 16-bit personal computers continued to be sold after 1992).

\section{Estimation Method}

To analyze product lifetimes in the personal computer industry, an event-history approach based on the statistical framework of failure time analysis is used (e.g., Cox and Oakes 1984, Helsen and Schmittlein 1993). The advantage of this approach is that it takes into account both the occurrence and the timing of an event while estimating the effects of explanatory variables. In addition, truncated data can be accommodated within the estimation procedure. Analyses were performed using the SAS LIFEREG procedure (SAS Institute 1988).
In this case, the "event" of interest is the withdrawal of a product from the marketplace. Since the assembled personal computer database includes all desktop personal computer product introductions and withdrawals between 1974 (i.e., the beginning of this industry) and 1992, the only situation in which an event will not be observed is when a product is withdrawn after the observation period covered by the database (i.e., after 1992). In other words, some observations may be rightcensored.

The duration time studied is the length of the product life-cycle. For the available data, this duration time is calculated as the year of product withdrawal (determined as the year after introduction in which total domestic and international annual product sales is zero) less the year of product introduction. For example, the product lifetime for IBM's PC XT desktop model (introduced in 1983 and withdrawn in 1987) is four years.

The usual approach associated with duration time analysis is used to statistically model product lifetimes (e.g., see Helsen and Schmittlein 1993). Letting $T_{k}$ be the duration time for product $k$, the hazard rate $h(t)$ is

$$
h(t)=f(t) /[1-F(t)],
$$

where $f(t)$ is the probability density function and $F(t)$ is the cumulative distribution associated with the random variable $T_{k}$. Here, $h(t)$ is the conditional likelihood that product withdrawal occurs at duration time $t$, given 
that it has not occurred in the interval $(0, t)$. Using a standard assumption (e.g., see Helsen and Schmittlein 1993), the duration time p.d.f. is specified as a Weibull distribution

$$
f(t)=\alpha \beta t^{\beta-1} e^{-\alpha t^{\beta}}, \quad \alpha, \beta>0,
$$

with hazard rate $h(t)=\alpha \beta t^{\beta-1}$.

To estimate the effects of explanatory variables the accelerated failure time model is used. As noted by Cox and Oakes (1984), this model is equivalent to the proportional hazards regression model for the assumed Weibull duration time distribution function. The accelerated failure time model assumes that the effects of explanatory variables on a duration time distribution is multiplicative (i.e., linear in logarithms) on the duration time. In line with most applications, this scale function is assumed to be of an exponential form, $e^{X^{\prime} \theta}$, where $\mathbf{X}$ is a vector of explanatory variables and $\boldsymbol{\theta}$ a vector of unknown parameters. As noted by Helsen and Schmittlein (1993), $\theta_{j}$ represents the constant proportional effect of $x_{j}$ on the hazard rate. These coefficients can be interpreted as a quasi-elasticity (i.e., the percentage change in the hazard rate for a unit change in the corresponding explanatory variable $x_{j}$ ) by calculating $100\left[\exp \left(\theta_{j}\right)-1\right]$.

Thus, if $\tau_{0}$ is a duration time sampled from the baseline distribution, then the model to be estimated takes the form

$$
\log (T)=\lambda+\mathbf{X}^{\prime} \boldsymbol{\theta}+\sigma \log \left(\tau_{0}\right),
$$

where the parameters to be estimated are the vector $\boldsymbol{\theta}$, the intercept $\lambda$, and the scale constant $\sigma$. This model assumes that the log duration times are normally distributed, thus allowing for increasing and decreasing hazard rates across duration times. If the scale parameter estimate is less than one, then the hazard rate is nonmonotonic. For the assumed Weibull baseline distribution, the mean product life-cycle length for a model with no covariates can be estimated as $e^{\lambda} \Gamma(1+\sigma)$.

The model parameters are estimated by maximum likelihood using a Newton-Raphson algorithm. Estimates for the standard errors of the parameters are computed from the inverse of the observed information matrix. The ratio of a coefficient to its standard error approximates a $t$-statistic for a test of significance. Overall model fit is assessed using the likelihood ratio test, which compares the estimated model with explanatory variables against a model without explanatory vari- ables. This test statistic is distributed as a chi-square (with degrees of freedom equal to the number of explanatory variables) and is computed as twice the difference in model log-likelihood values.

\section{Analysis and Results}

As discussed in the introduction, the key research question is whether product lifetimes are systematically getting shorter over time. Following prior empirical studies (e.g., Qualls et al. 1981, Bayus 1992), product life-cycle lengths at various product market levels are statistically related to the year of product introduction to test this hypothesis. If product lifetimes are indeed shrinking, a negative coefficient for product introduction year is expected. The next three sections present analyses for product lifetimes defined at various product market levels.

\subsection{Product Technology and Product Model Lifetimes}

As suggested by Figures 3 and 4, directly analyzing product technology or product model lifetimes will not really be feasible because these life-cycles are relatively long (i.e., products with "old" technology continue to be sold after 1992). Instead, the time to peak sales is examined in this section (therefore, the duration time in Equation (3) is the year of peak sales less the year of product introduction).

From Figure 3 it is clear that product technology is not accelerating: the time to peak sales for 8-bit personal computers is 11 years, whereas the time to peak sales for 16-bit machines is 14 years (the 32-bit personal computer sales peak is sometime after 1992). This finding is also consistent with Intel's actual microprocessor development schedule (see Hof 1992, 1995). Contrary to reports by the popular press (e.g., Hof 1995), Intel does not seem to have accelerated the availability of new technology because new microprocessors continue to be introduced in approximately three-year increments, with volume shipments occurring a year after introduction. In many cases, estimates for future microprocessors are subject to revision (e.g., earlier estimates of the introduction dates for the 586/ Pentium underestimated the actual dates; see also Brandt 1993).

An analysis at the product model level was conducted by estimating the relationship between the time to peak sales associated with the various CPUs 


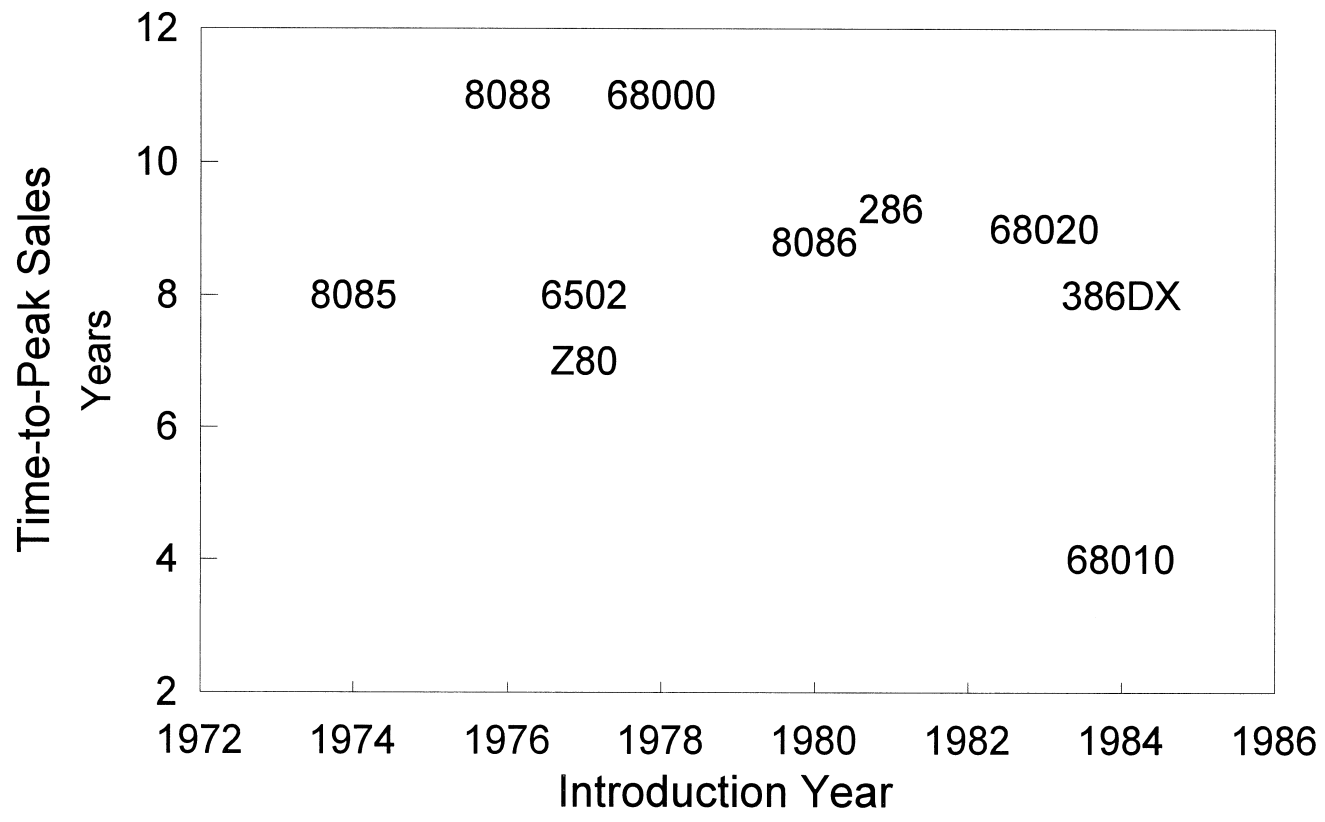

introduced between 1974 and 1992, and the product model year of introduction (e.g., see Figure 4). As suggested by Figure 5, the relationship between product introduction year and time to peak sales is insignificant. Since some observations are censored (i.e., the sales for some product models did not peak before 1992), this can be formally confirmed by estimating the duration model in Equation (3) (details are not reported here but are available upon request). This finding indicates that the time to peak sales for product models is not shrinking over time.

\subsection{Brand Model Lifetimes Within Manufacturers}

The statistical model in Equation (3) was estimated for the brand model lifetimes within 20 of the top market share leaders but for brevity is not reported here (details are available upon request). The mean brand model lifetimes for these manufacturers is reported in Table 1 (the mean brand model lifetime across all manufacturers is 3.67 years). With few exceptions (as noted in Table 1), product introduction year is not statistically related to product lifetime. This finding indicates that the leading personal computer manufacturers are not systematically shortening their own brand model lifetimes.

\subsection{Brand Model Lifetimes Across Manufacturers}

The duration model in Equation (3) was also estimated for brand model lifetimes across all manufacturers. If competing firms are not purposively shortening their own brand model lifetimes but are systematically pursuing strategies involving different product cycles, shrinking product lifetimes would be observed across manufacturers if the more recent entrants have relatively short product lifetimes as compared to established firms. To better understand observed brand model lifetimes across firms, two additional explanatory variables are considered. ${ }^{4}$

First, observed product lifetimes across manufacturers might be related to the entry timing of firms, since later entrants into this industry tend to introduce personal computer models that have shorter life-cycles than the products of firms already in the industry. For example, Table 1 (where the manufacturers are sorted in ascending order by year of firm entry) suggests that earlier entrants have larger mean product lifetimes than later entrants (e.g., compare the average of the first five and last five). As noted by Steffens (1994), these later

\footnotetext{
${ }^{4}$ As noted by one reviewer, relating other variables such as cumulative industry sales or number of competing firms to observed product lifetimes would also be of interest. However, these variables are monotonically increasing between 1974 and 1992 and thus are highly correlated with product introduction year, a key variable in this study. A complete analysis of the firm's product line decision is left for future research.
} 
Table 1 Mean Brand Model Lifetimes for Selected Personal Computer Manufacturers (in ascending order by year of firm entry)

\begin{tabular}{lcc}
\hline \multicolumn{1}{c}{ Manufacturer } & Country of Origin & $\begin{array}{c}\text { Mean Product } \\
\text { Life Cycle Length } \\
\text { (Years) }\end{array}$ \\
\hline Groupe Bull & France & 3.39 \\
Hewlett Packard & U.S.A. & 3.63 \\
IBM & U.S.A. & 5.47 \\
Tandy & U.S.A. & 3.74 \\
Apple & U.S.A. & 4.38 \\
Northgate & U.S.A. & $2.86^{1}$ \\
Digital Equipment & U.S.A. & 3.13 \\
NCR & U.S.A. & 3.42 \\
NEC & Japan & 4.63 \\
Epson & Japan & 3.36 \\
Sanyo & Japan & 3.19 \\
Compaq & U.S.A. & $3.74^{2}$ \\
Gateway 2000 & U.S.A. & 4.87 \\
Adv. Logic Research & U.S.A. & 3.34 \\
Dell & U.S.A. & 2.95 \\
Samsung & Korea & $2.45^{2}$ \\
Packard Bell & U.S.A. & 3.89 \\
Acer & Taiwan & 2.99 \\
Hyundai & Korea & 4.04 \\
Goldstar & Korea & 3.97 \\
\hline
\end{tabular}

${ }^{1}$ Although not reported here, a positive and significant coefficient for introduction year is exhibited by this manufacturer's products.

${ }^{2}$ Although not reported here, a negative and significant coefficient for introduction year is exhibited by this manufacturer's products.

entrants are faced with a maturing industry in which distribution is shifting from direct sales force activity (e.g., dealers, value-added resellers) to mass merchant outlets (e.g., mass merchants, superstores, consumer electronics, mail order). In addition, there is usually a limited supply of new components (such as CPUs) incorporating the latest technology (e.g., Brandt 1993, Steffens 1994). Thus, many later entrants choose to compete by changing their product model offerings more often than established firms to appeal to mass distributors and/or to update their products as key components become available (see Ziegler 1995, Armstrong 1996, Choi 1996). To test this hypothesis, brand model lifetime is statistically related to the firm's time of entry into this industry. Firm entry year for each product is defined as the year in which the manufacturer sold its first desktop personal computer. A negative coefficient for firm entry year is expected if later entrants tend to introduce personal computers that have shorter lifetimes than the products of firms already in the marketplace.

Second, product lifetimes may be related to the products that firms are introducing. With the exception of the initial years surrounding the birth of this industry, new and established firms can choose to introduce products based on various available technologies. In particular, firms must decide between introducing products based on the most advanced technology available, or based on an already existing technology. If a next-generation product is available, it is expected that a new product based on older technology will have a shorter market lifetime than it might have had if the next-generation technology were not available. For the total sample of personal computers, the first product of new firms tends to be based on older technologies (given that a next-generation technology was available, 46 percent of new firms introduced a personal computer model based on a preexisting technology generation, whereas only 24 percent of established firms introduced a personal computer model with old technology; $z$ $=22.5, p<0.01$ ). This, combined with the entry pattern of new firms shown in Figure 2, suggests that the likelihood of introducing products with old technology (and thus shorter product lifetimes) has increased over time. To capture the possible effect of firms introducing products based on preexisting technology, a variable defined as the year in which the next-generation CPU technology is available less the year of product introduction is used. Note that this variable can take on positive or negative values. For example, IBM's PC XT was introduced in 1983 with a 16-bit $8088 \mathrm{CPU}$; thus, the time before next generation technology is available for this product model is 2 years (i.e., 1985, the year in which 32-bit CPU technology was available, less 1983). A positive coefficient for this explanatory variable is expected if products based on "old" technology have shorter lifetimes than products with the most advanced technology available.

Table 2 reports the estimation results for two subsamples: first products of new firms and products of established firms. First products of new firms represent a special case, since multiple generations of technology are not available at every time point. In particular, "old" technology is not available during the early years in the evolution of this industry (for new firms, 70 percent of all the products introduced between 1974 and 1985 were 


\begin{tabular}{lcc}
\hline & $\begin{array}{c}\text { First Product of } \\
\text { New Firms }\end{array}$ & $\begin{array}{c}\text { Products of } \\
\text { Established } \\
\text { Firms }\end{array}$ \\
\hline Intercept & $72.020^{1}$ & $30.041^{2}$ \\
& $(15.458)$ & $(12.410)$ \\
Product Introduction Year & $-0.036^{1}$ & 0.002 \\
& $(0.009)$ & $(0.007)$ \\
Firm Entry Year & $n a^{3}$ & $-0.016^{1}$ \\
& & $(0.004)$ \\
Time Before Next Generation & & \\
Technology is Available & $0.035^{1}$ & $0.027^{1}$ \\
& $(0.008)$ & $(0.004)$ \\
Scale Parameter & $0.530^{1}$ & $0.494^{1}$ \\
& $(0.019)$ & $(0.012)$ \\
Log-Likelihood Ratio Statistic & $39.75^{1}$ & $50.97^{1}$ \\
Mean Product Lifetime & & \\
(Years) & 3.89 & 3.52 \\
\hline
\end{tabular}

${ }^{1}$ Significant at 0.01 level.

${ }^{2}$ Significant at 0.05 level.

${ }^{3}$ For this subsample, firm entry year is equivalent to product introduction year.

based on the most advanced technology available, whereas only 44 percent of all the products introduced between 1986 and 1992 had the newest technology; $z$ $=10.5, p<0.01$ ). Also, note that firm entry year is the same as product introduction year for new firms.

As shown in Table 2, the duration model provides a very good fit to the underlying data as evidenced by the significant log-likelihood ratio values. For new firms, the coefficients of product introduction year and time before next generation technology is available are statistically significant at better than the 0.01 level. However, the coefficient for product introduction year is not statistically related to the length of product life-cycles for established firms. Instead, product lifetimes for established firms are related to the entry timing of firms and the products that are being introduced. Together, these results indicate that the more recent entrants into this industry have products with shorter lifetimes than firms that have been in this industry for some time, and products based on "old" technology have shorter lifetimes than products with the newest technology. Using the coefficient estimates in Table 2 to calculate the quasielasticity transformation $100\left[\exp \left(\theta_{j}\right)-1\right]$, it is also clear that the time before next-generation technology is available is the dominant factor in explaining brand model lifetimes across firms selling desktop personal computers.

\section{Implications and Conclusions}

The statistical results across manufacturers are consistent with the popular press reports that personal computer lifetimes have declined over time. However, this empirical observation is not due to an underlying acceleration in product technology or product model lifetimes, nor is it due to individual firms systematically reducing the life-cycles of products within their lines. Instead, the first products of firms that have entered this industry in the more recent years tend to be based on previously existing technology, and, not surprisingly, these products have life-cycles that are shorter than those of established firms. This is also consistent with recent reports in the business press (e.g., Hardy 1995).

As with any empirical study, the findings in this paper are limited to the specific industry, product form, and time period analyzed. Still, there are some interesting implications that can be noted. First, the sales opportunity window in which to obtain a financial return on invested resources in this industry is not getting shorter over time. For firms in the personal computer industry, this finding suggests that there may be no need to increase continually the level of R\&D expenditures. Instead, a constant level of new product development activity is appropriate (see Meyer and Utterback 1993). Second, firms in this industry are not systematically shrinking the lifetimes of products within their own lines. This finding suggests that firms in the personal computer industry are balancing the costs and returns associated with their own individual product strategies (see also Lambert 1996). Third, the competitive environment in this industry is complex, with multiple generations of technology being available in the market at any time. This finding implies that purchase behavior in the personal computer market is complex (e.g., for a variety of reasons, some market segments may prefer products with old technology, even though newer technology is available).

Given that firms in the personal computer industry are not systematically reducing the lifetimes of products within their lines, it should not be surprising that 


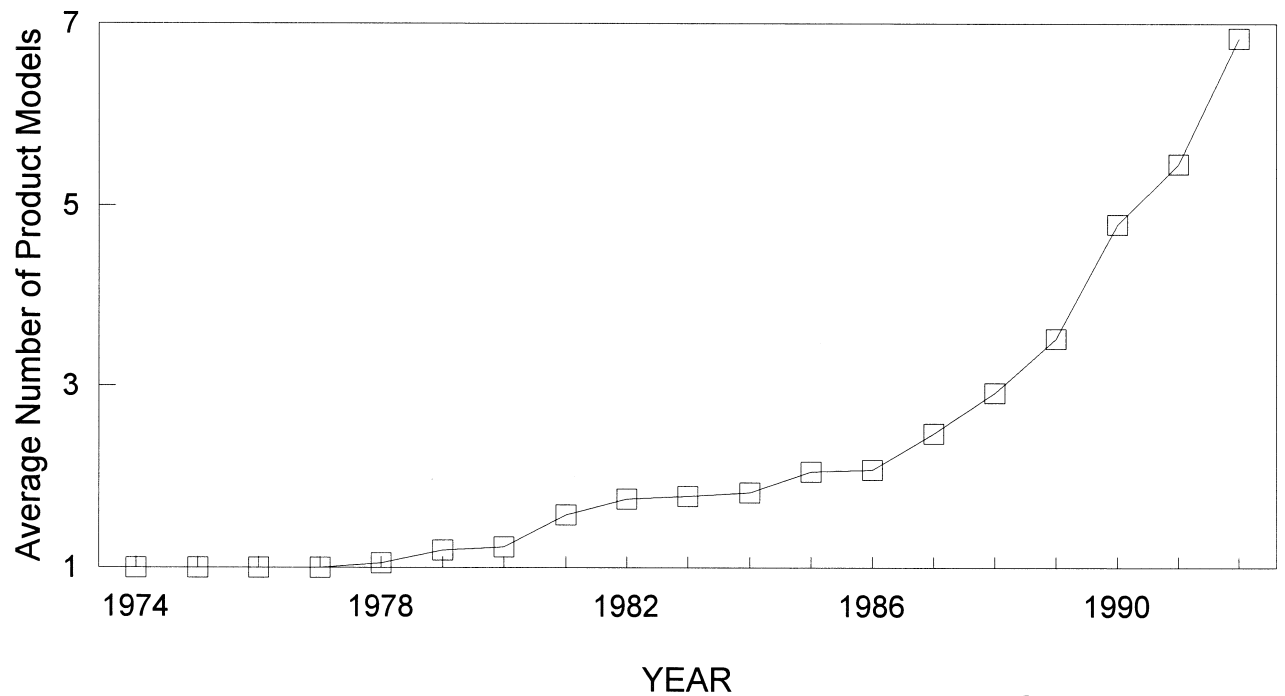

the average product line length for personal computer manufacturers has steadily increased over time (see Figure 6). Thus, firms are not consistently withdrawing products from the market at the same rate as they are introducing new products. Moreover, the business press indicates that only the manufacturers with full product lines are able to maintain shelf space in the mass distribution outlets (e.g., Armstrong 1996, Choi 1996).

For firms, these findings suggest that there may be no need to continually increase the level of R\&D expenditures. Instead, the immediate concern for firms is to make sufficient returns from increasing product line "complexity" (e.g., Child et al. 1991). Some firms in the personal computer industry are finding that the manufacturing and marketing costs associated with broad product lines are greater than the revenue associated with incremental demand from numerous product alternatives, and they are thus pruning the weaker products from their lines (e.g., Carlton 1993a). In addition, firms with products that have relatively short life-cycles continue to face strong competition on product features (e.g., Ramstad 1995) and still have problems forecasting demand (e.g., Carlton 1993b, Schneidawind 1993, King 1995).

For consumers, these conditions imply an increase in product options, configurations, and technologies. Unfortunately, this expanded choice also comes with greater confusion over the alternatives that are available (e.g., Carlton 1994, Hays 1994, Wildstrom 1996). This is especially the case for personal computers because the incremental "value" of new products over existing products may not be that large (e.g., Johnson 1993, McCartney 1994, Clark 1995).

Because the empirical setting for this study is limited to one technologically dynamic industry, future research should consider other markets and time periods before the findings discussed here can be generalized. In addition, a careful analysis of the product line decisions by firms over time would add to our understanding of product lifetimes. It is expected that factors such as competitive pressure (e.g., number of firms, number of products, industry concentration), market opportunity (e.g., installed base, industry growth rate, price trends), internal pressure (e.g., market share, firm age, time since last product introduction or withdrawal), and internal opportunities (e.g., firm sales growth, number of product models in line, available technology) will significantly influence a firm's decisions regarding "new" product introductions and "old" product withdrawals. These effects may also differ over time as the industry evolves.

It is hoped that the empirical analysis presented in this paper shows the potential dangers associated with blindly accepting conventional wisdom espoused by the popular press. The lesson in this case is: do not rush 
new products to market unless a careful analysis of the benefits and costs indicates that this is indeed the best strategy. ${ }^{5}$

${ }^{5}$ The financial support of UNC's CATO Center for Applied Business Research and the Roy and Alice H. Richards Bicentennial Professorship Fund is gratefully acknowledged. Thanks are also extended to Howard Susskind for his assistance in researching the personal computer industry, and to the anonymous reviewers.

\section{References}

Alsop, R., "Companies Get on Fast Track to Roll Hot New Brands," Wall Street Journal, July 10, 1986.

Armstrong, L., "Savior From Down Under?" Business Week, January $15,1996,85-86$.

Bayus, B., "Have Diffusion Rates Been Accelerating Over Time?," Marketing Letters, 3 , 3 (1992), 215-226.

_ , "Are Product Life Cycles Really Getting Shorter?" J. Product Innovation Management, 11 (1994), 300-308.

Brandt, R., "Intel: What a Tease-and What a Strategy," Business Week, February 22, 1993, 40.

Carlton, J., "Apple to Peel Away Confusion Over Its Existing Product Lines," Wall Street Journal, October 18, 1993a, B1, B3.

__, "Popularity of Some Computers Means Buyers Must Wait," Wall Street Journal, October 21, 1993b, B1, B12.

__ "Befuddled PC Users Flood Help Lines, and No Question Seems to be Too Basic," Wall Street Journal, March 1, 1994, B1, B6.

Child, P., R. Diederichs, F. Sanders, and S. Wisniowski, "The Management of Complexity," McKinsey Quarterly, 4 (1991), 52-68.

Choi, A., "Digital to Exit Home-Computer Sector, Focus on PCs for Business Customers," Wall Street Journal, January 30, 1996, A3, A8.

Cimento, A., J. Kluge, and L. Stein, "Excellence in Electronics," McKinsey Quarterly, 3 (1993), 29-40.

Clark, D., "Intel Puts Chip Under Pentium Brand, Meaning Some Won't Reap Its Benefits," Wall Street Journal, September 20, 1995, B8.

Cox, W., "Product Life Cycles as Marketing Models," J. Business, 40 (1967), 375-384.

Cox, D. and D. Oakes, Analysis of Survival Data, Chapman and Hall, New York, 1984.

Dumaine, B., "How Managers Can Succeed Through Speed," Fortune, February 13, 1989, 54-59.

Eisenhardt, K., "Making Fast Strategic Decisions in High Velocity Environments," Acad. Management J., 32 (1989), 543-576.

Foster, R., Innovation: The Attacker's Advantage, Summit Books, New York, 1986.

Fraker, S., "High Speed Management for the High Tech Age," Fortune, March 5, 1984, 62.

Goldman, A., "Short Product Life Cycles: Implications for the Marketing Activities of Small High-Technology Companies," RED Management, 12, 2 (1982), 81-89.

Grubler, A., "Long Term Patterns and Discontinuities," Technological Forecasting and Social Change, 39 (1991), 159-180.

Hardy, Q., "Cirrus Logic's Poor Outlook Sends Stock Tumbling, Clouds Industry," Wall Street Journal, December 29, 1995, B3.
Hays, L., "Too Many Computer Names Confuse Too Many Buyers," Wall Street Journal, June 29, 1994, B1, B6.

Helsen, K. and D. Schmittlein, "Analyzing Duration Times in Marketing: Evidence for the Effectiveness of Hazard Rate Models," Marketing Sci., 11 (1993), 395-414.

Hof, R., "Inside Intel: It's Moving at Double-Time to Head Off Competitors," Business Week, June 1, 1992, 86-94.

_, "Intel: Far Beyond the Pentium," Business Week, February 20, 1995, 88-90.

Johnson, B., "Intel Puts Pentium Chip on a Pedestal," Advertising Age, 3 (1993), 46.

Kerin, R., P. R. Varandarajan, and R. Peterson, “First-Mover Advantage: A Synthesis, Conceptual Framework, and Research Propositions," J. Marketing, October (1992), 33-52.

King, R., "Packard Bell's Woes Reflect a Bad Bet, Not a Marketwide Drop in PC Demand," Wall Street Journal, November 29, 1995, B10.

Lambert, D., "First, Fast, and On-Time. The Path to Success; Or is It?" Presented at Hewlett Packard's Project Management Conference, 1996.

Langlois, R., "External Economies and Economic Progress: The Case of the Microcomputer Industry," Business History Rev., 66 (1992), $1-50$.

Levitt, T., "Exploit the Product Life Cycle," Harvard Business Rev., November-December (1965), 81-96.

_ , "Innovative Imitation," Harvard Business Rev., September-October (1966), 63-70.

McCartney, S., "Computer Buyers Are Smart to be Suspicious," Wall Street Journal, September 12, 1994, B1, B8.

Meldrum, M., "Marketing High-Tech Products," European J. Marketing, 29, 10 (1995), 45-58.

Meyer, M. and J. Utterback, "The Product Family and the Dynamics of Core Capability," Sloan Management Review, Spring (1993), 2947.

Patterson, M., Accelerating Innovation, Van Nostrand Reinhold, New York, 1993.

Pierz, K., “Benchmarking New Product Development Funding," J. Product Innovation Management, 12 (1995), 43-53.

Polli, R. and V. Cook, "Validity of the Product Life Cycle," J. Business, 42 (1969), 385-400.

Qualls, W., R. Olshavsky, and R. Michaels, "Shortening of the PLCAn Empirical Test," J. Marketing, 45 (1981), 76-80.

Ramstad, E., "PC Makers Looking for New Ways to Stand Out," News $\mathcal{E}$ Observer, September 17, 1995, 6F.

Rosegger, G. and R. Baird, "Entry and Exit of Makes in the Automobile Industry, 1895-1960," OMEGA, 15, 2 (1987), 93-102.

Rosenau, M., "Speeding Your New Product to Market," J. Consumer Marketing, 5 (1988), 23-36.

SAS Institute, SAS / STAT User's Guide 6.03, SAS Institute, Cary, NC, 1988.

Schnaars, S., Managing Imitation Strategies, Free Press, New York, 1994.

Schneidawind, J., "Hottest PCs Can't Keep up with Demand," USA Today, May 25, 1993, 1B.

Stalk, G., "Time-The Next Source of Competitive Advantage," Harvard Business Rev., 66 (1988), 41-51.

MAnAgement Science/Vol. 44, No. 6, June 1998 
BAYUS

Analysis of Product Lifetimes

Stalk, G. and A. Webber, “Japan's Dark Side of Time," Harvard Business Rev., 71 (1993), 93-102.

Steffens, J., New Games: Strategic Competition in the PC Revolution, Pergamon Press, New York, 1994.

Utterback, J., Mastering the Dynamics of Innovation, Harvard Business School Press, Boston, MA, 1994.

Verity, J., "Deconstructing the Computer Industry," Business Week, November 23, 1992, 90-100. von Braun, C., "The Acceleration Trap," Sloan Management Review, Fall (1990), 49-58.

- "The Acceleration Trap in the Real World," Sloan Management Rev., Summer (1991), 43-50.

Wildstrom, S., “Wanted: A PC for the Masses," Business Week, January 15, 1996, 18.

Ziegler, B., "PC Makers' Big Push Into the Home Market Comes at Risky Time," Wall Street Journal, November 1, 1995, A1, A9.

Accepted by Ralph Katz; received May 1996. This paper has been with the author 5 months for 2 revisions. 